\title{
Design of a prototype of an engine mechanism with rotating cylinders
}

\author{
Miroslav Blatnický ${ }^{1}$ and Ján Dižo ${ }^{1, *}$ \\ ${ }^{1}$ University of Žilina, Faculty of Mechanical Engineering, Department of Transport and Handling \\ Machines, Univerzitná 8215/1, 01026 Žilina, Slovak Republic
}

\begin{abstract}
In this article, authors focus on the design and construction of a real prototype of an engine mechanism with rotating cylinders and its using mainly in piston combustion engines. It is assumed, that the normal force of a piston will be completely eliminated, because the swing angle of a connecting rod will equal to zero during the whole working cycle, since the connecting arm of the piston moves just the cylinder axis. It will by allowed by the conceptual design of the mechanism presented in this article. As rotating blocks of cylinders concurrently act as a flywheel, it is proposed, that in this way there is possible to save the mass of additional flywheels. Moreover, liquid cooling system is not necessary, because the rotating cylinders sufficiently transfer heat to ambient air. In addition, the output of torque will be reached without necessity of gear transmission, which results to decreasing of needs of mechanism lubrication. Other advance of the designed mechanism are two outputs. The first output is low-speed and it goes out from rotating cylinders, i. e. from the slidercrank mechanism with revolutions $n_{1}$. The other output is high-speed, from the crankshaft with revolutions $n_{2}$. Because of more favourable properties of the mechanism, authors have decided to create a real device to confirm all mentioned advantages of the mechanism by the suitable way.
\end{abstract}

\section{Introduction}

Kinematics deals with the mechanical movement of bodies, it examines the change in the relative positions of the bodies regardless of the force effect in space and time. It forms a part of classical mechanics. In kinematics, the causes of movement are ignored, i.e. force actions are not examined. In kinematics, therefore, only geometric properties (not mass) of points or bodies are considered. We will apply this knowledge to the 3-D model of the kinematic mechanism with rotating cylinders with the help of a CAD computer programme.

The disadvantage of all piston combustion engines is the fact that the larger the angle of the connecting $\operatorname{rod} \beta$, the more loaded by side pressure the piston and other engine parts, and thus, the torque is created by less pressure force. Another disadvantage of these engines is the fact that the pistons perform a reciprocating motion relative to the cylinders, which puts increased demands on the smooth running of the engine by the distributed set of flywheel extra weights. The above-described fact encourages the creation of the

\footnotetext{
*Corresponding author: jan.dizo@ffstroj.uniza.sk
} 
construction of such a kinematic structure of the machine especially for the piston engines, which would eliminate the above-mentioned drawbacks of the piston engine designs [1-3].
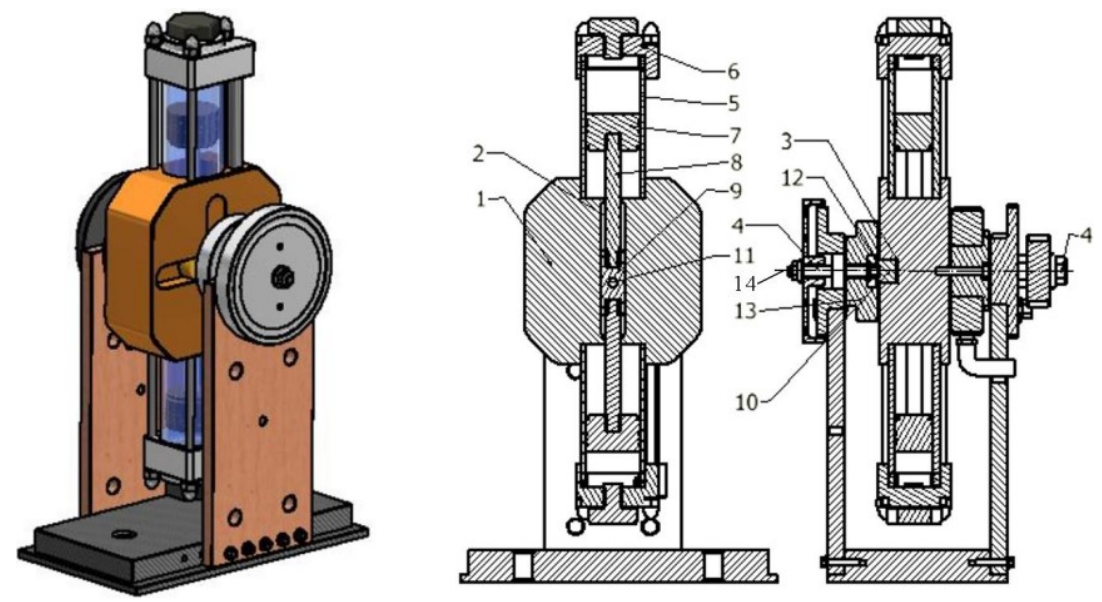

Fig. 1. A 3D model of engine design with rotating cylinders (left) and section through this model (right).

As a result of this effort, a kinematic arrangement of the mechanism with rotating cylinders will be proposed and used especially in piston combustion engines in the modification of a spark-ignition or diesel engine and a two or four stroke engine; compressors and hydraulic pump constructions as well as in compressed air engines.

\section{Basic idea of the design and its methodology}

The design of a kinematic arrangement of the mechanism with rotating cylinders (Fig. 1) consists of a Scotch yoke (slotted link mechanism) formed by a plate (1) with a skew line crossing arrangement of the connecting rod slot (2) and auxiliary slot (3), in whose apparent "intersection" an axis of rotation of the scotch yoke mechanism is located (4). In the axis of rotation of the mechanism (4) a shaft is located in the bearing and the bearing is mounted in the frame or chassis of the device. Radially to the axis of rotation (4) of the mechanism, two opposed cylinders (5), each ended by the cylinder head (6), are attached to the scotch yoke mechanism. The pistons (7), which are interconnected by a common connecting rod (8) passing through the connecting rod slot (2), are mounted in the cylinders (5), with the connecting rod slot nut (9) being located in the centre of the connecting rod (8). An auxiliary nut (10) is located in the auxiliary slot (3). The first pin (11) of the crankshaft (13) fits into the connecting rod nut hole (9), and the second pin (12) of the crankshaft (13) fits into the auxiliary nut hole (10). A rotation axis (14) of the crankshaft (13) is located between the first (11) and second (12) crankshaft pins. The crankshaft is mounted in its axis of rotation in a bearing which is mounted in a frame or chassis of the device. The axis of rotation (4) of the scotch yoke and the axis of rotation (14) of the crankshaft are not coaxial. The crankshaft (13) radius $r$ is equal to $1 / 4$ of the piston (7) stroke. The axis of rotation (4) of the scotch yoke mechanism is output with the revolutions $n_{1}$. The axis of rotation (14) of the crankshaft is output with revolutions (1) [4]:

$$
n_{2}=2 \cdot n_{1}
$$

Such a kinematic arrangement of the mechanism with rotating cylinders is useful for combustion two- and four-stroke engines in the modification of spark-ignition or diesel 
engine driven by compressed air as well as steam. The use of the kinematic arrangement of the mechanism with rotating cylinders of this design is also applicable for compressors and pumps. The advantages of the kinematic arrangement of the mechanism with rotating cylinders are evident from its effects, which are manifested externally. The effects consist essentially in the complete eliminating the side (normal) force on the piston since the angle $\beta$ of the connecting rod has zero value. This is due to the piston connecting rod moving only in the cylinder axis. Furthermore, the concept of this solution implies that the rotating blocks of cylinders and pistons act as a flywheel. This means that the engine will weigh at least $15 \mathrm{~kg}$ less compared to the above-mentioned concepts (no need to use additional flywheels). There is also no need for a liquid cooling circuit because the rotating cylinders remove heat to the ambient air in which they are moving. By this, sufficient air circulation by increasing the Grossman factor for removing heat from the rotating cylinders is ensured. The torque output from the rotating cylinders is achieved without gearing, which results in reducing mechanism lubrication demand and also increasing the efficiency of the mechanism due to the friction reduction.
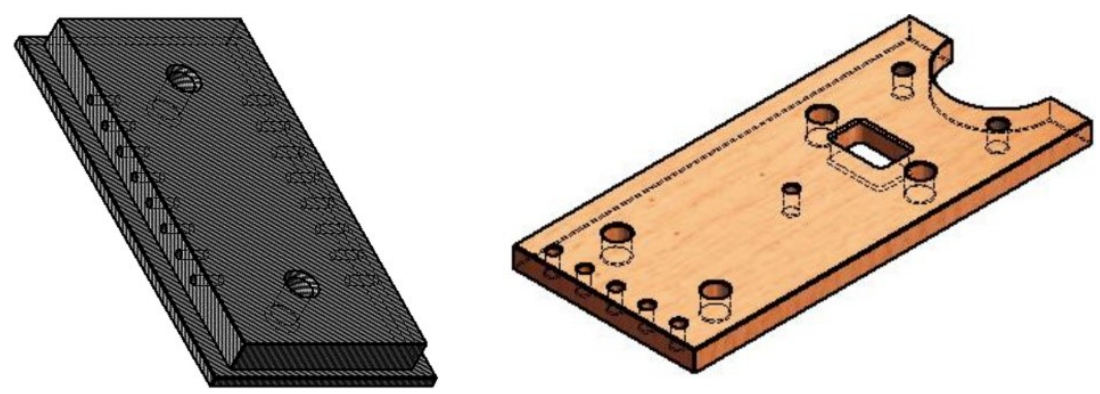

Fig. 2. A mechanism base plate (left) and its foot (right).

The first component created was a base plate (Fig. 2 left). Two through holes $\varnothing 12 \mathrm{~mm}$ used for fixing the plate to the frame, and threaded holes M5x15 mm for fixing the plate to the front and rear feet were drilled in. Subsequently, the chamfers $1 \times 45^{\circ}$ were created at the whole plate and chamfers $2 \times 45^{\circ}$ were created in the holes $\varnothing 12 \mathrm{~mm}$. The second component is formed by two feet (Fig. 2 right), which hold the entire rotating mechanism. Both have the same size, but the holes and slots are spaced differently. The holes used for fixing to the base plate are M5x10 mm and the holes for mounting gripping are M7x10 mm. Finally, an opening for the air intake valve has been milled into the front foot.

The third component is formed by the front and rear mounting (Fig. 3 left) for the rotation of the mechanism. Counterbored holes were drilled in the mounting for its gripping to the feet by socket head cap screws. Other holes were also drilled into them, which were then further processed to the required values under the ball bearing. Finally, the outer and inner edges were chamfered to $1 \times 45^{\circ}$.
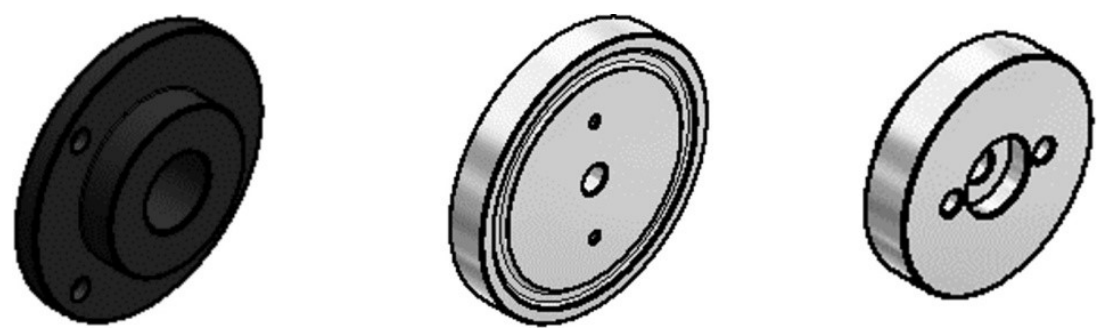

Fig. 3. Front and rear mounting (left), a rear wheel (middle) and the crank mechanism wheel (right). 
The other components (Fig. 3 middle and right) were the rear wheel (middle) and the crank mechanism wheel (right), which were connected to each other with mounting by the M6x50 mm bolt and an M6 flange nut. The rear wheel has a circular groove and two holes for additional mechanism gripping on the front surface. The crank mechanism was made as a cylinder with three holes on the front surface. The middle one serves for mounting by means of a connecting screw and two for inserting $\varnothing 4 \mathrm{~mm}$ pins which guide the sliding keys in the grooves of the central switchgear.
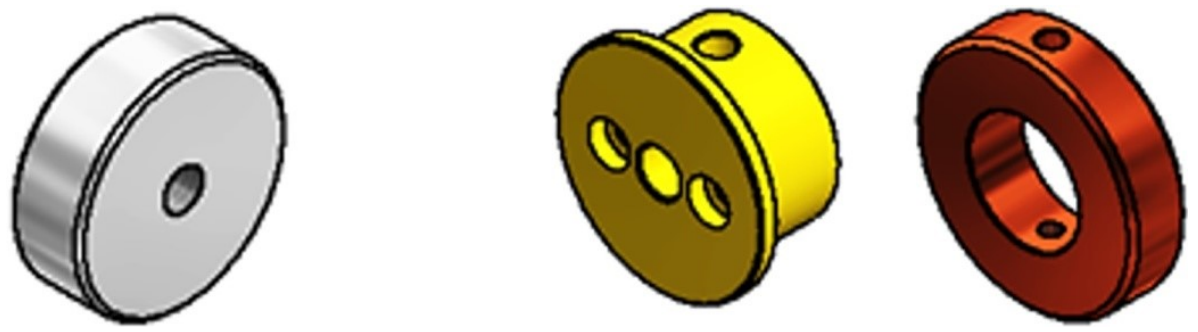

Fig. 4. Front wheel (left) and the central switchgear components (right).

Another section of the components was the creation of a front wheel (Fig. 4) with a drilled hole for M10x65 mm connecting screw that passes through the front mounting and connects two components of the central switchgear. The inner part of the switchgear was firmly connected to the central switchgear by means of two socket head cap screws and a hole for the compressed driving air has been drilled into its cylindrical circumference. The outer part can rotate freely around the inner circumference and there were also two holes for the distribution of the driving air drilled into it. An air inlet valve was placed into one of the holes.
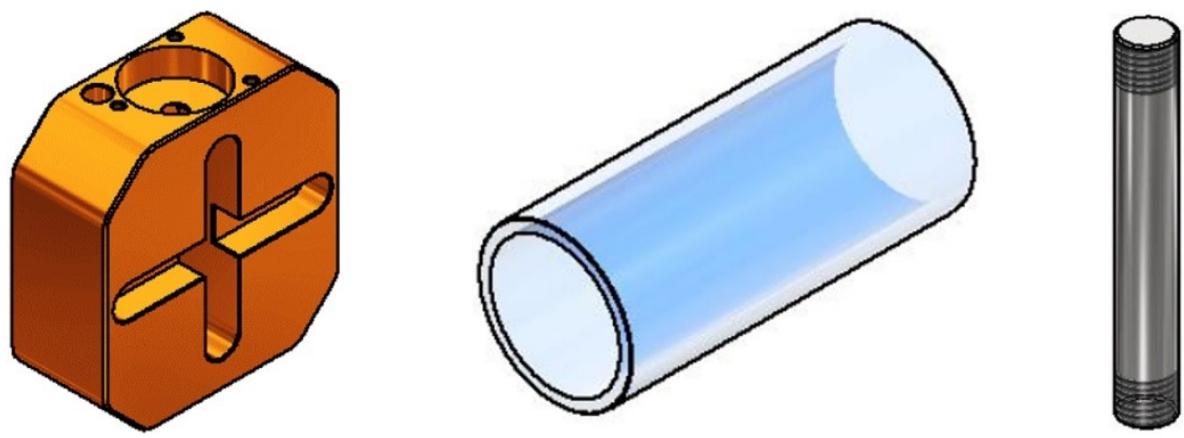

Fig. 5. A central switchgear (left), a cylinder (in the middle) and a connecting rod (right).

Another component is a cube shaped central switchgear (Fig. 5 left), in which the holes for countersinking the cylinders and the key groove are milled. The deeper hole controls the piston movement and the other - shallower groove controls the rotation of the entire mechanism. M4x10 mm holes were also drilled into the switchgear to screw in the retaining bolts to grip the cylinder heads. The last $10 \times 10 \mathrm{~mm}$ hole was used to fit the supply pipe.

Next, a piston cylinder (Fig. 5 in the centre), was made of a glass cylinder and shortened to the desired length. The glass cylinder was chosen to provide the visibility of the pistons movement. This was followed by the formation of a common connecting rod (Fig. 5 right) by means of two connecting rods. These were connected at one end by an inner key (Fig. 6 left) and at the other end with a piston (Fig. 6 in the centre). 

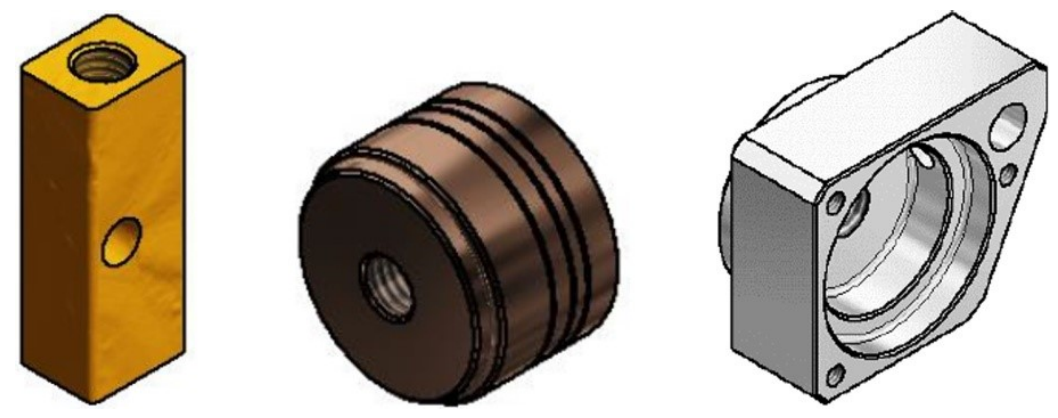

Fig. 6. An inner key (left), a piston (in the middle) and a cylinder head (right).

The last proposed part of the rotating cylinder mechanism was the cylinder head (Fig. 6 right). The cylinder heads were made to a given shape and connected to the cylinder and the rest of the mechanism by means of fastening screws. Subsequently, a plug was screwed into the centre hole to ensure pressure in the cylinder. The manufactured mechanism (Fig. 7) works on compressed air to ensure purity. In the case of an internal combustion engine, the ignition device would be screwed in place of the plug.

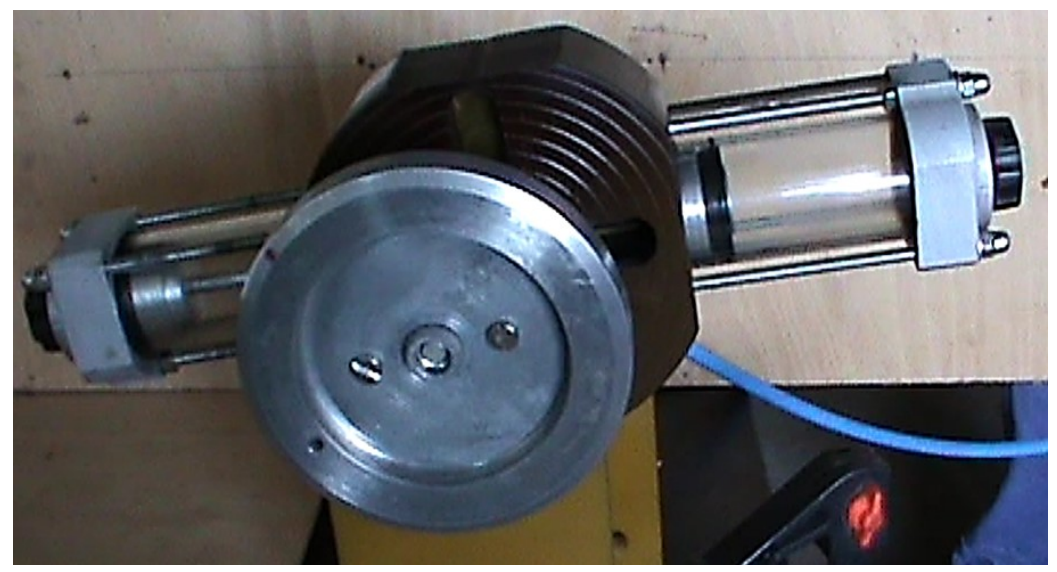

Fig. 7. Image of a real prototype of a rotating cylinder mechanism captured during its performance test.

The future research activities related with this special design of a mechanism will be focused on analysis of individual part of the mechanism in term of stress distribution during its operation process. It will be analysed using FE computational method [5, 6]. Further, rotational movement of the device causes certain level of noise and vibration. These dynamics effects will be studies by means of MBS software [7, 8]. Implementing flexible bodies created in a FE software to the MBS model will allow to evaluate individual parts of the mechanism under various load conditions.

\section{Conclusion}

The aim of the article was the design of all members of the kinematic arrangement of the mechanism with rotating cylinders. From the figures and texts above, it can be stated that this goal has been met. The advantages of the kinematic arrangement of the mechanism with rotating cylinders are evident from its effects, which are manifested externally. The effects consist essentially in the complete eliminating the side (normal) force on the piston since the angle $\beta$ of the connecting rod has zero value. This is due to the piston connecting 
rod moving only in the cylinder axis. Furthermore, the concept of this solution implies that the rotating blocks of cylinders and pistons act as a flywheel. This means that the engine will weigh at least $15 \mathrm{~kg}$ less compared to the above-mentioned concepts (no need to use additional flywheels. There is also no need for a liquid cooling circuit because the rotating cylinders remove heat to the ambient air in which they are moving. The torque output from the rotating cylinders is achieved without gearing, which results in reducing mechanism lubrication demand and also increasing the efficiency of the mechanism due to the friction reduction. The mechanism with rotating cylinders has also the advantage of providing two outputs at the engine modifications. The first output is low-speed, from the rotating cylinders, i.e., from a scotch yoke mechanism with revolutions $n_{1}$. The second output is a high-speed, from crankshaft with revolutions $n_{2}$. Another substantial advantage of the kinematic arrangement of the mechanism with rotating cylinders is the cylinders reciprocating motion removal. This is due to the offset of the crankshaft axis relative to the axis of the cylinder's rotation and due to the fact that crankshaft radius $r$ is equal to $1 / 4$ of the piston stroke. This causes the piston to move to the top dead centre by approaching along the circular path with simultaneous rotation of the cylinder.

The advantages of the kinematic arrangement of the mechanism with rotating cylinders can emerge by its application in combustion engines by adding the relevant components associated with the fuel supply, its spark and exhausted gas routing. Another application is offered for steam-driven engines. The mechanism is complemented by steam supply components. Another application can be in compressors. The mechanism is complemented by gas supply and compressed exhausted gas components as well as components for output torque of the scotch yoke mechanism or crankshaft. Another application is available for hydraulic pumps by completing the mechanism with liquid suction and discharge components as well as torque output components in the scotch yoke mechanism or crankshaft.

Presented technical solution is currently given a utility model no. SK 24-2017 U1.

This work was supported by the Cultural and Educational Grant Agency of the Ministry of Education of the Slovak Republic in the project No. KEGA 023ŽU-4/2020: Development of advanced virtual models for studying and investigation of transport means operation characteristics.

\section{References}

1. D. Dardalis, M. Hall, R. Matthews, A. Basu, T. Ozel, SAE Technical Papers 2019

2. A. Gerlach, H. Rottengruber, R. Leidhold, IECON 2018, 44 (2018)

3. P. Kukuca, D. Barta, R. Labuda, T. Gechev, MATEC Web of Conferences 244 (2018)

4. Utility model no. SK 24-2017, Kinematic layout of a mechanism with rotating cylinders

5. P. Fabian, J. Gerlici, J. Masek, P. Marton, Komunikacie 15, 7 (2013)

6. P. Št’astniak, M. Moravčík, P. Baran, L. Smetanka, MATEC Web of Conferences 157 (2018)

7. V. Hauser, O. Nozhenko, K. Kravchenko, M. Loulova, J. Gerlici, T. Lack, Procedia Engineering 192 (2017)

8. V. Hauser, O. Nozhenko, K. Kravchenko, M. Loulová, J. Gerlici, T. Lack, Manufacturing Technology 17, 3 (2017) 